\title{
Erratum to: S-type ignimbrites with polybaric crystallisation histories: the Tolmie Igneous Complex, Central Victoria, Australia
}

\author{
J. D. Clemens · W. D. Birch • R. J. Dudley
}

Published online: 13 July 2011

(c) Springer-Verlag 2011

\section{Erratum to: Contrib Mineral Petrol \\ DOI 10.1007/s00410-011-0652-1}

The original article was published with some errors. These are listed below as corrected:

1. The correct name and initials of the third author is R. J. Dudley.

2. The correct last sentence of Fig. 6 caption should read 'As discussed in the text, the conditions of early crystallisation lie within the light grey field'.

3. The third line in page 12 (right column and second para) should refer to Fig. 10 and not 'Fig. 12'.
4. Delete the last sentece of the caption to Fig. 8. See correction 5 (below) for the colour coding of symbols.

5. The colour coding in the graphs of Figs. 8-10 and $12-14$ is as follows:

Green squares-low-Ba Ryans Creek Ignimbrite Red squares-high-Ba Ryans Creek Ignimbrite Blue dots-Toombullup Ignimbrite Yellow triangles-Molyullah Ignimbrite Mauve diamonds-Myrrhee porphyritic microgranodiorite Black circles-Hollands Creek Ignimbrite

The online version of the original article can be found under doi:10.1007/s00410-011-0652-1.

J. D. Clemens $(\square)$

Department of Earth Sciences, University of Stellenbosch, Private Bag X1, Matieland, Stellenbosch 7602, South Africa e-mail: jclemens@sun.ac.za

W. D. Birch

Geosciences Section, Museum Victoria, PO Box 666,

Melbourne, VIC 3001, Australia

R. J. Dudley

School of Earth Sciences, University of Melbourne, Melbourne,

VIC 3010, Australia 